\title{
Uptodate about techniques for the neonatal screening values of bilirubin levels used for jaundice
}

\author{
Actualități despre tehnicile de măsurare a bilirubinei la \\ nou-născut pentru depistarea icterului \\ Vlad DIMA ${ }^{1}$, Anca Angela SIMIONESCU ${ }^{2,3}$, Ana Maria Alexandra STĂNESCU ${ }^{4}$, \\ Andreea CALOMFIRESCU-AVRAMESCU ${ }^{1}$, Dora BOGHIȚOIU ${ }^{5,6}$ \\ ${ }^{1}$ Neonatologie, Spitalul Clinic Filantropia, Bucureşti, România \\ ${ }^{2}$ Obstetrică-Ginecologie, Universitatea de Medicină şi Farmacie „Carol Davila“, Bucureşti, România \\ ${ }^{3}$ Obstetrică-Ginecologie, Spitalul Clinic Filantropia, Bucureşti, România \\ ${ }^{4}$ Medicină de familie, Universitatea de Medicină şi Farmacie „Carol Davila“, Bucureşti, România \\ ${ }^{5}$ Spitalul Clinic de Urgenţă pentru Copii „Grigore Alexandrescu”, Bucureşti, România \\ ${ }^{6}$ Pediatrie, Universitatea de Medicină şi Farmacie „Carol Davila“, Bucureşti, România
}

\begin{abstract}
Neonatal jaundice is one of the main factors responsible for maternal stress and the increasing length of hospitalization in the first days after birth. Therefore, accurately determining bilirubin values with low costs investment is essential to guide a quickly and effectively treated. This article aims to review the main techniques used in current practice to measure bilirubin levels in the newborn and establish the correlation between treatment and monitoring. Thus, we will present the working methods for transcutaneous bilirubin measurement, continuous transcutaneous bilirubin monitoring simultaneously with vital signs and serum bilirubin measurement. Furthermore, we will present the main differences in the evaluation in normal weight and premature newborns. In conclusion, the measurement of bilirubin in the newborn contributes to initiating the phototherapy and the decrease of kernicterus cases with significant neurological consequences.
\end{abstract}

Keywords: icterus, bilirubin, laboratory tests

\section{REZUMAT}

Icterul neonatal este principalul responsabil pentru stresul matern şi pentru creșterea numărului de zile de internare în maternitate, în primele zile după naștere. De aceea, determinarea cu precizie a valorilor bilirubinei, cu costuri reduse, este esențială pentru a ghida tratamentul rapid şi eficient. Obiectivul acestui articol este revederea principalelor tehnici utilizate în practica curentă pentru măsurarea titrului bilirubinei la nou-născut şi corelația cu nevoia de tratament şi monitorizare. Astfel, vom prezenta metodele de lucru pentru măsurarea bilirubinei transcutanat, monitorizarea continuă transcutanată a bilirubinei simultan cu semnele vitale şi măsurarea bilirubinei serice. Vom prezenta principalele diferențe in evaluarea la 
normoponderali şi la nou-născuții prematuri. În concluzie, măsurarea bilirubinei la nou-născut contribuie la stabilirea indicației de fototerapie şi la scăderea cazurilor de kernicterus cu consecințe neurologice importante.

Cuvinte cheie: icter, bilirubină, teste de laborator

\section{INTRODUCERE}

Icterul neonatal este principalul responsabil pentru creșterea numărului de zile de internare în maternitate, în primele zile după naștere, pentru normoponderalii la termen. Aproximativ unul din 10 nou-născuți va dezvolta icter care să necesite fototerapie [1]. Astfel, icterul neonatal, definit ca un exces de bilirubină în sânge la naștere sau la scurt timp după aceea, are un impact financiar mare, în special pentru centrele medicale cu resurse reduse. Trei sferturi dintre decesele cauzate de icter apar în Africa subsahariană și Asia de Sud [2]. Grupările polare din structura bilirubinei care o fac mai stabilă sunt implicate în legarea intramoleculară a hidrogenului, care scade solubilitatea sa și face pigmentul aproape insolubil la pH de 7,4, ca al apei. Dubla ionizare în mediul alcalin, solubilitatea scăzută în apă și tendința sa de agregare și precipitare la $\mathrm{pH}$ fiziologic, în special pH-ul acid, s-a crezut că sunt factorii cheie în apariția toxicității bilirubinei [3]. Anionul bilirubinei neconjugate este agentul neurotoxicității acesteia. Anionul se leagă de fosfolipidele (gangliozidele) membranelor plasmatice neuronale, care cauzează leziuni, ceea ce permite apoi intrarea mai multor anioni în neuron. Anionul intracelular de bilirubină se leagă la fosfolipidele membranei organitelor celulare, determinând afectarea metabolismul energetic și moartea celulară.

Kernicterul (encefalopatie determinată de bilirubină) este o complicație gravă a depunerii bilirubinei la nivel cerebral, cu risc de deces și consecințe neurologice pe termen scurt și lung [4].

Cristale de bilirubină au fost găsite în celulele creierului nou-născuților care au murit în urma encefalopatiei icterice și concentrații de bilirubină de $2 \mathrm{mg} / \mathrm{dl}$ (34 $\mu \mathrm{mol} / \mathrm{l}-1 \mathrm{mg} / \mathrm{dl}=17,1 \mu \mathrm{mol} / \mathrm{l}$ ) [5]. În studiul lui, Wennberg a sugerat că formarea complexelor reversibile între monoanionul bilirubinei și membranele celulare este importantă și în dezvoltarea encefalopatiei bilirubinemice [6].

Bariera hemato-encefalică joacă, fără îndoială, un rol în protejarea nou-născutului de leziunile cerebrale, însă integritatea sa este imposibil de măsurat clinic. Cantitatea de albumină disponibilă pentru a lega anionul bilirubinei neconjugate și prezența altor anioni care pot înlocui bilirubina la nivelul situsurilor de legare cu albumina sunt, de asemenea, importante. Nu se știe dacă există un nivel fix de bilirubină deasupra căruia apar întotdeauna leziuni cerebrale. Termenul de icter nuclear descrie constatarea patologică a colorării nucleilor ganglionilor bazali și a nucleilor cerebrali, precum și sindromul clinic determinat de apariția leziunilor cronice ale creierului datorate hiperbilirubinemiei. Termenul de encefalopatie acută bilirubinică descrie semnele și simptomele evoluției leziunilor cerebrale la nou-născut. Riscul encefalopatiei bilirubinice este mic la nou-născuții sănătoși, chiar și la niveluri de $25-30 \mathrm{mg} / \mathrm{dl}$ (430-516 mmol/l) ale bilirubinei. Riscul depinde de durata hiperbilirubinemiei, concentrația de albumină serică, bolile asociate, acidoza și concentrațiile de anioni concurenți, cum ar fi sulfizoxazol și ceftriaxonă. Prematurii prezintă un risc mai mare decât nounăscuții la termen din cauza frecvenței mai mari a bolilor asociate care afectează integritatea barierei hemato-encefalice, a nivelurilor reduse de albumină și a scăderii afinității situsurilor de legare a albuminei. Din aceste motive, „nivelul de schimb“ (nivelul la care este posibil să apară encefalopatia bilirubinică) la nounăscuții prematuri poate fi mai mic decât cel al unui nou-născut la termen.

De aceea, determinarea cu precizie a valorilor bilirubinei cu costuri reduse este esențială pentru a ghida tratamentul eficient pentru icterul neonatal în maternitățile cu resurse financiare reduse.

Datorită monitorizării bilirubinei și fototerapiei, kernicterul a scăzut în mod semnificativ în multe țări. Între timp, mulți nou-născuți născuți în țările în curs de dezvoltare sunt încă afectați de kernicter din cauza lipsei accesului la echipamentele medicale. Deși fototerapia este principalul tratament pentru icterul neonatal, trebuie remarcat faptul că trebuie evitată atât fototerapia excesivă, cât și insuficientă, dar este adesea dificilă monitorizarea nivelurilor precise de bilirubină în timpul fototerapiei.

În acest articol ne-am propus să revedem principalele tehnici utilizate în practica noastră curentă de măsurare a titrului bilirubinei la nou-născut și corelația cu nevoia de tratament și monitorizare.

\section{MĂSURAREA TRANSCUTANATĂ A BILIRUBINEI (TCB)}

Valorile bilirubinei pot fi măsurate prin tehnici noninvazive, transcutanate, care au la bază principiul lumi- 
nii reflectate de pielea nou-născutului, și prin tehnici invazive, dozări din sânge ale bilirubinei totale, precum și ale fracțiilor acesteia (directă și indirectă). Bilirubina transcutanată (TcB) este metoda cea mai utilizată pentru screeningul nou-născuților, în timp ce bilirubina serică (TsB) reprezintă metoda cea mai fidelă de diagnostic a icterului.

Când lumina este transmisă pielii, strălucirea luminii reflectate poate fi măsurată pentru a asigura o determinare obiectivă a culorii pielii, iar aceste principii au fost aplicate pentru a prezice nivelurile de TSB folosind bilirubinometre transcutanate portabile. De DeLuca și colab. rezumă informațiile disponibile despre măsurarea și interpretarea valorilor pentru bilirubinometria transcutanată [7]. Există două dispozitive comercializate în prezent în Statele Unite, Draeger JM 103 (Draeger Medical, Hatboro, PA) și un nou model, JM 105; a fost comercializat în Europa și dispozitivul BiliChek (Philips Children's Medical Ventures, Monroeville, PA). Deși aceste instrumente folosesc algoritmi și măsurători tehnice diferite, principiile de funcționare sunt aceleași. Detaliile modului în care funcționează aceste bilirubinometre sunt furnizate în studiile realizate de DeLuca, Maisels și colaboratorii $[7,8]$, iar noi ne propunem să prezentăm aspectele clinice relevante.

Măsurătorile bilirubinei transcutanate se corelează bine cu valorile bilirubinei serice la populațiile mixte și la nou-născuții indiferent de vârsta de gestație (Figura 1), inclusiv la nou-născuții prematuri sub 32 de săptămâni de gestație $[9,10]$. Măsurătorile transcutanate nu sunt la fel de exacte ca cele serice și niciodată nu le pot substitui. TcB este o măsurare a spectrelor luminii reflectate ale pielii și țesuturilor subcutanate, nu a valorii bilirubinei serice, și trebuie utilizată doar ca instrument de screening pentru a determina dacă trebuie măsurată bilirubina serică. Când este folosit ca instrument de screening, măsurătorile TcB ne pot ajuta să răspundem la întrebările „Este acest nou-născut la risc?” și „Ar trebui să obțin o valoare serică a bilirubinei la acest nounăscut?" [8].

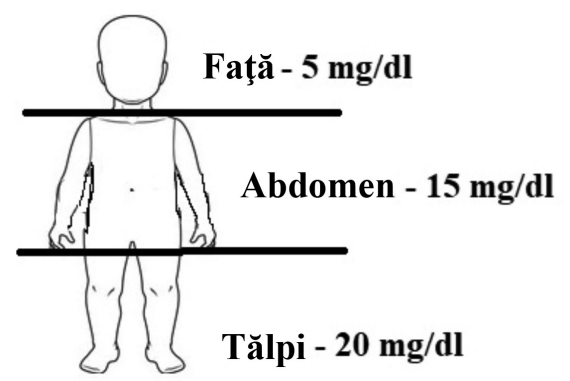

FIGURA 1. Corelația icterului cutanat cu nivelurile bilirubinei transcutanate

Măsurătorile TcB reduc în mod semnificativ numărul de recoltări pentru determinările serice necesare la toți nou-născuții $[7,9,10]$. Bilirubina transcutanată determinată înainte de externare oferă o estimare bună a riscului de hiperbilirubinemie ulterioară [11] și reprezintă un bun indicator pentru planul de managemnt al nou-născutului la domiciliu $[7,12,13]$. Fiind o tehnică neinvazivă, măsurătorile TcB pot fi repetate de mai multe ori în timpul spitalizării după naștere și oferă informații utile despre viteza de creștere a bilirubinei. Valorile obținute se plasează pe nomograme și se interpretează în contextul clinic al nou-născutului.

Într-un studiu comparativ pe 250 nou-născuți peste 36 de săptămâni de gestație, Șimșek și colaboratorii au aratat că, pentru formele ușoare de icter care nu necesită fototerapie, diferența medie între bilirubina serică și valorile bilirubinei transcutanate a fost semnificativ mai mică comparativ cu diferențe la cazurile care necesită fototerapie și la care valoarea bilirubinei este de $5,2 \mathrm{mg} / \mathrm{dl}[14]$.

Valorile bilirubinei transcutanate sunt influențate de o serie de factori precum: gradul de pigmentare al pielii (la pacienții hiperpigmentați pot apărea valori fals pozitive), vârsta de gestație (la prematuri sub 32 de săptămâni de gestație si la nou-născuții cu o greutate scăzută la naștere poate fi utilizată doar ca screening, dar sensibilitatea este mai mică), valorile serice ale bilirubinei (la valori serice de peste $15 \mathrm{mg} / \mathrm{dl}$ tind să dea valori mai scăzute față de cele serice), fototerapia efectuată anterior (măsurarea transcutanată nu este recomandată după începerea fototerapiei, iar dacă este utilizată se măsoară pe zonele pielii care au fost acoperite), locul de măsurare (pe frunte sau la nivelul sternului; mai recent, la nou-născuții prematuri, a fost realizat un studiu cu măsurarea interscapulară) $[15,16]$.

Într-un review sistematic, Nagar și colab. au arătat, pe 1319 nou-născuți cu vârsta de gestație de peste 34 de săptămâni, care începuseră fototerapia, o corelație moderată între valorile TcB și TsB (bilirubina serică totală) [9], dar studiile au analizat vechile aparate de măsură transcutanată.

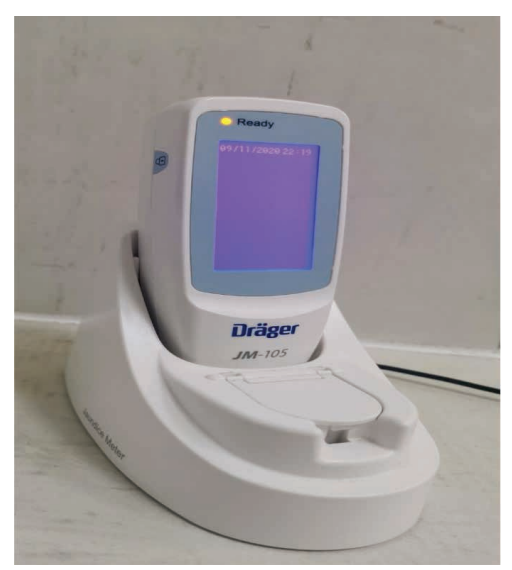

FIGURA 2. Bilirubinometru transcutanat Drager JM-105 (colecție personală dr. Dima Vlad) 


\section{MONITORIZAREA CONTINUĂ TRANSCUTANATĂ A BILIRUBINEI (SIMULTAN CU SEMNELE VITALE)}

Recent, au fost folosite metode colorimetrice bazate pe imaginile obținute cu o cameră de smartphone pentru măsurarea concentrației de bilirubină $[17,18]$. Metodele colorimetrice sunt convenabile și neinvazive, dar există dificultăți din punctul de vedere al preciziei. Mai mult, este dificil să se facă măsurători corecte ale bilirubinei în timpul fototerapiei cu bilirubinometre portabile și cu ajutorul unui smartphone. Diverse dispozitive portabile cu materiale organice au fost dezvoltate datorită progreselor în tehnologia materialelor. În special, dispozitivele portabile care pot detecta semne vitale multiple la nou-născuți, cum ar fi SpO2, electroencefalogramele și frecvența respirației, au fost dezvoltate în ultimii ani. Dispozitivele sunt compuse dintr-un hibrid de materiale organice și anorganice care a obținut o aderență ridicată a contactului moale între dispozitiv și tegumente.

Inamory și colab. au dezvoltat un dispozitiv multivital portabil care are capacitatea de a măsura simultan ritmul cardiac (HR) și saturația oxigenului (SpO2). HR și $\mathrm{SpO} 2$ sunt semne vitale comune care sunt frecvent măsurate în procedurile medicale. Studiul lor efectuat pe 50 de nou-născuți a arătat că dispozitivul brevetat de ei, care cântărește doar $16 \mathrm{~g}$, poate fi utilizat pentru măsurarea bilirubinei transcutanate, însă acuratețea măsurătorilor are nevoie de îmbunătățiri, măsurătorile nefiind încă validate [19].

\section{MĂSURAREA BILIRUBINEI SERICE}

Măsurarea bilirubinei serice totale este unul dintre cel mai des efectuate analize de laborator la nou-născut. Măsurarea concentrației TSB arată o variație considerabilă în rândul diferitor analizoare clinice [20] și depinde de valorile de calibrare a aparatului, dar rămâne cea mai bună metodă de diagnostic a icterului.

Datele privind diferențele de nivel ale bilirubinei serice atunci când sunt măsurate din eșantioane capilare sau venoase sunt contradictorii. Toate datele publicate cu privire la relația nivelurilor crescute ale bilirubinei legate de encefalopatia bilirubinemică sau rezultatul dezvoltării hiperbilirubinei neonatale se bazează pe nivelurile bilirubinei capilare. Astfel, pentru luarea deciziilor clinice, probele de sânge capilar sunt standardul de aur și nu există niciun motiv să întârzie inițierea tratamentului pentru a obține o altă probă de sânge venos pentru a „confirma” nivelul crescut al bilirubinei capilare.

Fracțiile bilirubinei ce pot fi determinate din sângele capilar sau venos sunt bilirubina directă (BD) și bilirubina indirectă (BI). Bilirubina directă se referă la bilirubina care reacționează direct cu acid sulfanilic diazotizat (fără adăugarea unui agent accelerator), bilirubina conjugată este solubilă în apă prin legarea cu acidul glucuronic din ficat. $\mathrm{O}$ mică porțiune din bilirubină conjugată se numește delta bilirubină și este legată covalent la albumină. Determinările bilirubinei directe estimează concentrația totală a bilirubinei conjugate și a delta bilirubinei. Când există un nivel ridicat de bilirubină neconjugată (de obicei măsurată ca bilirubină totală la nou-născut), o parte din bilirubina neconjugată va reacționa cu reactivul diazoid fără adăugarea accelerantului, determinând valori crescute directe ale bilirubinei, care supraestimează concentrația de bilirubină conjugată.

Bilirubina indirectă nu este hidrosolubilă, dar este liposolubilă. Aceasta se leagă de albumină și este transportată la nivelul hepatocitelor. Solubilitatea este crescută odată ce se combină cu albumina. Valorile bilirubinei indirecte se obțin prin calcularea diferenței dintre bilirubina totală serică și bilirubina directă.

Metoda cea mai utilizată în laboratoare este metoda Vitros, dezvoltată inițial de Kodak, care măsoară nivelurile de bilirubină conjugată și neconjugată prin spectrofotometrie directă [20]. Nomogramele redactate în urma studiilor efectuate au poziționat valoarea percentilei 99 pentru nivelurile bilirubinei conjugate la $0,5 \mathrm{mg} / \mathrm{dl}$, iar pentru bilirubina directă la $2,1 \mathrm{mg} / \mathrm{dl}$. Un studiu recent, realizat de Davis și colab., a arătat că nou-născuții cu atrezie biliară au valori crescute ale bilirubinei directe sau conjugate la scurt timp după naștere, dar, după cum s-a menționat în studiul respectiv, $96 \%$ dintre nou-născuții au niveluri ale bilirubinei conjugate între 0,5 și 1,9 mg/dl fără a avea un diagnostic patologic [21]. În mod uzual, bilirubina directă trebuie să fie o treime din bilirubina totală pentru a nu fi patologică. Bilirubina indirectă se determină prin scăderea din valoarea bilirubinei totale a celei directe.

Fiind o metodă invazivă, măsurarea serică a bilirubinei se realizează doar atunci când nou-născutul se află la risc înalt de a dezvolta icter nuclear. Trebuie să se determine un nivel al bilirubinei (transcutanat sau seric) la fiecare nou-născut care prezintă icter în primele 24 de ore după naștere [22].

\section{CONCLUZII}

Metodele de măsurare a bilirubinei s-au diversificat în ultimii ani, dar necesită o investiție financiară permanentă pentru achiziționarea aparaturii și instruirea personalului. Datorită monitorizării bilirubinei și utilizării fototerapiei, kernicterul a scăzut în mod semnificativ ca frecvență în multe țări. Riscul de encefalopatie hiperbilirubinemică rămâne crescut in cazul nounăscuților din țările subdezvoltate și din regiunile cu acces limitat la metode precise de măsurare a bilirubinei și de tratament corespunzător al icterului. 


\section{BIBLIOGRAFIE}

1. Olusanya BO, Kaplan M, Hansen TWR. Neonatal hyperbilirubinaemia: a global perspective. Lancet Child Adolesc Health. 2018;2(8):610-620.

2. Olusanya BO, Teeple S, Kassebaum NJ. The Contribution of Neonatal Jaundice to Global Child Mortality: Findings From the GBD 2016 Study. Pediatrics. 2018;141(2):e20171471.

3. Brites D, Brito MA. Bilirubin toxicity. In: Stevenson DK, Maisels MJ, Watchko JF, eds. Care of the jaundiced neonate. New York: McGraw Hill, 2012:115.

4. Li Q, Deng X, Yan J, et al. Neonatal Severe Hyperbilirubinemia Online Registry in Jiangsu Province: protocol for a multicentre, prospective, open, observational cohort study. BMJ Open. 2021;11(2):e040797.

5. Claireaux AE, Cole PG, Lathe GH. Icterus of the brain in the newborn. Lancet. 1953;265(6798):1226-1230.

6. Wennberg RP. Cellular basis of bilirubin toxicity. NY State J Med. 1991; 91(11):493-496.

7. DeLuca D, Engle W, Jackson G. Transcutaneous bilirubinometry: hepatology research and clinical developments. New York: Nova Biomedical, 2013.

8. Maisels MJ, Engle WD, Wainer S, et al. Transcutaneous bilirubin levels in an outpatient and office population. J Perinatol. 2011;31(9):621-624.

9. Nagar G, Vandermeer B, Campbell S et al. Reliability of transcutaneous bilirubin devices

\section{Conflict of interest: none declared Financial support: none declared}

in preterm infants: a systematic review. Pediatrics. 2013;132(5):871-81.

10. Maisels MJ. Noninvasive measurements of bilirubin. Pediatrics. 2012;129(4):779-781.

11. Maisels MJ, Deridder JM, Kring EA, Balasubramaniam M. Routine transcutaneous bilirubin measurements combined with clinical risk factors improve the prediction of subsequent hyperbilirubinemia. J Perinatol. 2009;29(9):612-617.

12. Maisels MJ, Clune S, Coleman K, et al. The natural history of jaundice in predominantly breast-fed infants. Pediatrics. 2014;134(2):e340-345.

13. Engle WD, Jackson GL, Stehel EK, Sendelbach DM, Manning MD. Evaluation of a transcutaneous jaundice meter following hospital discharge in term and near-term neonates. J Perinatol. 2005;25(7):486-490.

14. Şimşek FM, Narter F, Ergüven M. Comparison of transcutaneous and total serum bilirubin measurement in Turkish newborns. Turk J Pediatr. 2014; 56(6):612-617.

15. Wainer S, Rabi Y, Parmar SM, et al. Impact of skin tone on the performance of a transcutaneous jaundice meter. Acta Paediatr. 2009;98(12):1909-1915.

16. Yaser A, Tooke L, Rhoda N. Interscapular site for transcutaneous bilirubin measurement in preterm infants: a better and safer screening site. J Perinatol. 2014;34(3):209-212.
17. Taylor JA, Stout JW, de Greef L, et al. Use of a Smartphone App to Assess Neonatal Jaundice. Pediatrics. 2017; 140(3):e20170312.

18. Munkholm SB, Krøgholt T, Ebbesen F, Szecsi PB, Kristensen SR. The smartphone camera as a potential method for transcutaneous bilirubin measurement. PLoS One. 2018;13(6):e0197938.

19. Inamori G, Kamoto U, Nakamura F, et al. Neonatal wearable device for colorimetrybased real-time detection of jaundice with simultaneous sensing of vitals. Sci Adv. 2021;7(10):eabe3793.

20. Lo SF, Jendrzejczak B, Doumas BT; College of American Pathologists. Laboratory performance in neonatal bilirubin testing using commutable specimens: a progress report on a College of American Pathologists study. Arch Pathol Lab Med. 2008; 132(11):1781-1785.

21. Davis AR, Rosenthal P, Escobar GJ, Newman TB. Interpreting conjugated bilirubin levels in newborns. $J$ Pediatr. 2011 Apr;158(4):562-565.e1.

22. American Academy of Pediatrics Subcommittee on Hyperbilirubinemia. Management of hyperbilirubinemia in the newborn infant 35 or more weeks of gestation. Pediatrics. 2004;114(1):297-316. 